\title{
NEW RECORDS OF PHLEBOTOMINE SAND FLIES (DIPTERA: PSYCHODIDAE) FROM ECUADOR
}

\author{
Lynn A. Jones, Lee W. Cohnstaedt, Lorenza Beati, Rommy Terán, Renato León, and \\ Leonard E. Munstermann \\ (LAJ, LEM) Division of Epidemiology of Microbial Diseases, School of Public Health, Yale \\ University, New Haven, Connecticut 06520 U.S.A. (LEM); (LWC) Center for Medical, Agricultural \\ and Veterinary Entomology, Agricultural Research Service, USDA, Gainesville, Florida 32608 \\ U.S.A.; (LB) Institute of Arthropodology and Parasitology, Georgia Southern University, \\ Statesboro, Georgia 30460, U.S.A.; (RT, RL) Institute of Microbiology, School of Biological and \\ Environmental Sciences, Universidad San Francisco de Quito, Quito 17-1200-841, Ecuador \\ Leonard E. Munstermann: leonard.munstermann@yale.edu
}

\begin{abstract}
The number of recorded phlebotomine sand fly species in Ecuador has nearly doubled during the past 20 years as a result of surveys. In 2005, a sand fly survey of two localities, Tiputini in the Amazon rain forest and Paraiso Escondido in the Pacific coastal lowland forest, resulted in the capture of 25 species. New records for Ecuador consisted of five species from the Amazonian region and one from Paraiso Escondido. The Amazonian species were Nyssomyia richardwardi (Ready and Fraiha), Psathyromyia dreisbachi (Causey and Damasceno), Psathyromyia runoides (Fairchild and Hertig), Trichophoromyia pabloi (Barretto, Burbano and Young), and Trichopygomyia witoto (Young and Morales). The Pacific coastal lowland species was Psathyromyia punctigeniculata (Floch and Abonnenc).
\end{abstract}

\section{Keywords}

Lutzomyia; Brumptomyia; species distribution

Ecuador encompasses $283,560 \mathrm{~km}^{2}$, has an estimated population of approximately 13 million and spans three major ecological zones. The latter are created by the Andes Mountain range, which divides the country longitudinally. The eastern side of the Andes range consists primarily of tropical rain forests typical of the Amazon basin, whereas the western coastal region includes scrub and mixed lowland vegetation. The third zone is located in highland valleys circumscribed by the Andes.

Rodríguez (1950, 1953, 1956), aware of the importance of leishmaniasis in Ecuador, published the first inventories of Ecuadorian sand flies and described two new species. Later, Arzube (1960) listed 16 species for eight Ecuadorian provinces. Young (1979) reported 39 species of sand flies in Ecuador, and the surveys of Young and Rogers (1984) added seven more. Alexander et al. (1992) reported an additional 14 species to raise the total to 60. At present, 63 species are listed in the database of CIPA (Computer-aided Identification of Phlebotomine Sand Flies of the Americas, http://cipa.snv.jussieu.fr). For comparison, the richness of the sand fly fauna from the surrounding countries is higher than that currently reported from Ecuador. Peru to the south has 131 species (Cáceres et al. 2000), Brazil to the east lists 221 (http://cipa.snv.jussieu.fr), and Colombia has 150 including 140 species of Lutzomyia (sensu Young and Duncan 1994), eight Brumptomyia and two Warileya (Bejarano 2007). In the Colombia listing, 42 are new species records from 
a single province-Putumayo Province in the Amazon River watershed (Barretto et al. 2000). This indicated that Ecuador has not yet been surveyed adequately for sand fly biodiversity.

Phlebotomine sand fly species of medical interest in Ecuador and associated with leishmaniasis transmission include Lutzomyia gomezi (Nitzulescu), Lutzomyia hartmanni (Fairchild and Hertig), Nyssomyia trapidoi (Fairchild and Hertig), Pintomyia maranonensis (Galati, Cáceres and Le Pont), Pintomyia serrana (Damasceno and Arouck), and Lutzomyia ayacuchensis (Cáceres and Galati). In the Pacific lowland forest region of Paraiso Escondido (one focus of the current report), the species of concern was $N$. trapidoi (Le Pont et al. 1994). Because the species of highest density was $N$. trapidoi, it was indicated as the probable vector of the local leishmaniasis cases (Mouchet et al. 1994, Le Pont et al. 1994). Specimens of Lutzomyia castanea (Galati and Cáceres), P. maranonensis and P. serranacollected in the Amazonian region of Zumba near the Peruvian border-were considered possible vectors of leishmaniasis. The majority of specimens in these collections were $P$. serrana and were found within habitations, often biting during the day (Le Pont et al. 1994b). Lutzomyia ayacuchensis was identified as the main vector of cutaneous leishmaniasis in the Andean region of Paute in the central province of Azuay (Takaoka et al. 1990, Gomez and Hashiguchi 1991, Hashiguchi et al. 1991).

In recent years, cases of leishmaniasis have been recorded in 83\% (20/24) of Ecuador's provinces, including all of the six provinces in the Amazon basin (Calvolpina et al. 2004). The highest incidence rate of leishmaniasis cases has occurred in the western coastal region, where it increased 75\% from 2000 to 2004. Of the 63 sand fly species listed for Ecuador, 15 are considered anthropophilic (human feeding) and are suspected vectors of leishmaniasis (Calvopina et al. 2004). The species of Leishmania that have been associated with epidemics of leishmaniasis in Ecuador are phylogenetically diverse and include Leishmania (Viannia) panamensis Lainson and Shaw, $L$. $(V$.) guyanensis Floch and $L$. $(V$.) braziliensis Vianna, as well as $L$. (Leishmania) mexicana Biagi and $L$. (L.) amazonensis Lainson and Shaw (Bañuls et al. 1999, Calvopina et al. 2004).

The ecological landscape of Ecuador is complex. Coupled with multiple species of potential sand fly vectors and species of Leishmania parasites, subsequent development of an epidemiological risk map for human disease has been very difficult. Critical to development of these maps is determining which insect vector species are present and where they are distributed.

Recently, the taxonomy of New World sand flies has undergone a thorough revision (Galati 2003). In the earlier scheme of Young and Duncan (1994), approximately 400 species were subsumed under the genus Lutzomyia. These were separated into 26 subgenera or species groups. Galati's revision raised many of Young and Duncan's subgenera to generic status and, in a cladistic analysis of morphological characters (Galati 1990), clarified the systematic relationships among the Young and Duncan subgenera and groups. The Galati version has received support from more recent comparisons of ribosomal gene sequences (Beati et al. 2004).

\section{Materials and Methods}

Phlebotomine sand flies were collected from two forest sites: the Tiputini Biodiversity Station, Universidad San Francisco de Quito (http://192.188.53.69/tiputini/) located in the Orellana Province, approximately $300 \mathrm{~km}$ east of Quito $\left(0^{\circ} 38^{\prime} \mathrm{S}, 76^{\circ} 9^{\prime} \mathrm{W}\right.$; elev. $\left.233 \mathrm{~m}\right)$ and a Pacific lowland forest close to the community of Paraiso Escondido, approximately $10 \mathrm{~km}$ southeast of Puerto Quito in Pichincha Province $\left(0^{\circ} 5^{\prime} 34^{\prime \prime} \mathrm{N}, 7^{\circ} 3^{\prime} 48^{\prime \prime} \mathrm{W}\right.$; elev. $\left.548 \mathrm{~m}\right)$. The 
Tiputini site was located within the upper reaches of the Amazon basin and consisted of a mix of tropical rain forest, seasonally flooded forests and swamps. The forest site near Puerto Quito was a relatively disturbed zone with patches of secondary forest near subsistence agriculture (cacao, coffee and palm) and animal husbandry. Sand flies were retrieved from two traps at Tiputini and from 14 traps at the Puerto Quito location. Collections were made with standard Center for Disease Control and Prevention (CDC) light traps. Sand flies were sorted at the field site and preserved in $80 \%$ ethanol.

In the laboratory, specimens were prepared for slide mounts with slight modifications from those described by Young and Duncan (1994) and Cáceres and Villaseco Castro (2002). Each specimen was cleared with hot $10 \% \mathrm{KOH}$, transferred through a phenol-ethanol series and mounted in euparal on thick glass slides. Identifications were based on the keys of Young and Duncan (1994) and Galati (2003). Type specimens were not available for examination during the course of the study. Nomenclature followed the classification system of Galati (2003); the nomenclature of Young and Duncan (1994) was listed for comparison in Table 1. Voucher specimens consisting of slide mounts and of specimens in $80 \%$ ethanol were held at the Yale School of Public Health for later deposition at the Entomology Division, Yale Peabody Museum of Natural History, New Haven, Connecticut.

Species distributions indicated in Fig. 1 and remarks associated with each species below were distilled from Young and Duncan (1994) unless otherwise noted.

\section{Results}

Twenty-five phlebotomine sand fly species were identified from the two sites (Table 1). The Tiputini collections contained 10 species, five of which were new country records. The Paraiso Escondido (Pichinde Province) collections near Puerto Quito yielded 15 species, 11 of which had previously been collected from that locality (Le Pont et al. 1994). The following three species were known from other localities in Ecuador but had not yet been encountered in Paraiso Escondido: Psathromyia barrettoi (Mangabeira), Micropygomyia trinidadensis (Fairchild and Hertig) and Dampfomyia vespertilionis (Newstead) (Le Pont et al. 1994).

At Paraiso Escondido, only Psathyromyia (Oophoromyia) punctigeniculata (Floch and Abonnenc) was a new record for Ecuador. The presence of $P$. punctigeniculata in Paraiso Escondido expands its range to the western front of the Andes mountains, whereas all other records of this species were restricted to the eastern side. The additional distribution records include sites along the western slopes of the Andes Mountains, throughout the Amazon Basin, western Panama and along the northern coast of Colombia.

Five species were collected at the Tiputini Biodiversity Station, Orellana Province, Ecuador. Trichopygomyia witoto (Young and Morales) was known only from the type specimen, a male, collected in Leticia at the southern border of Colombia where it meets with Peru and Brazil. Barretto et al. (2000) collected two additional males and one female in the southern Colombian province of Putumayo. The current record integrates into the known range and represented a first report in Ecuador. Trichophoromyia pabloi (Barretto, Burbano and Young) was first described in 2002 from Putumayo, Colombia. This species is morphologically similar to other members of the genus, such as T. napoensis. Additional morphological and molecular studies of the closely related species in this genus are necessary in order to clarify species delineations. This record extends the range approximately $125 \mathrm{~km}$ south. Psathyromyia (Xyphomyia) dreisbachi (Causey and Damasceno) is distributed throughout the Amazon region and has been found in nonAmazon areas in Colombia, Venezuela, Brazil, Peru and French Guiana. This was the first 
record in Ecuador and represented a range extension of approximately $280 \mathrm{~km}$ to the west. Nyssomyia richardwardi (Ready and Fraiha 1981) was first recorded by Barretto et al. (2000) in the Amazonas Province of Colombia. The current collection was the first record of $N$. richardwardi in Ecuador and expanded the list of its locations in the Amazon basin. This record is further evidence of a continuous distribution of this species throughout the known range. Psathyromyia (Oophoromyia) runoides (Fair-child and Hertig) is distributed throughout the Amazon basin and has been recorded in Colombia, Brazil and Peru. The new collection record in Tiputini, Ecuador indicates the species has a continuous distribution throughout its known range in the Amazon basin.

\section{Discussion}

Four of the six newly recorded species have been reported to feed on humans. Their status as vectors of leishmaniasis remains unknown. As more extensive surveys in Ecuador are undertaken, additional species records will undoubtedly document a sand fly diversity that is comparable to the other Andean countries. For example, the extensive survey of Alexander et al. (1992), listing 60 species, did not include any inspections in the Amazonian forests of the Eastern Region. By comparison, a single collection episode $350 \mathrm{~km}$ to the northeast in Aracuara, Caqueta State, Colombia and located at the edge of the Amazonian basin recovered 35 species indigenous to Amazonian forests (Ferro and Morales 1998).

Several pairs of taxa were of unresolved status. One of these pairs was Lutzomyia carrerrai carrerai (Barretto) and Lutzomyia carrerai thula (Young), both subspecies of which are known from Ecuador and differ by morphological characters and geographic range. Initial DNA analyses indicated that these were actually distinct species (Dujardin and Le Pont 2000). In the current study, both taxa were collected and morphologically identified-a single specimen of $L$. carrerai thula was collected at the Pacific coastal site and $10 \mathrm{~L}$. carrerai carrerai at the Amazonian site. These observations corroborate the presence of morphological and geographic distinction of the two but lend no further evidence as to their species status. A similar question has arisen concerning the differentiation of $P$. serrana and Pintomyia robusta (Galati, Cáceres and Le Pont). The morphological differences between them were subtle and possibly some specimens identified as $P$. serrana are a smaller variety of $P$. robusta (Beati et al. 2004, Dujardin et al. 2004). Further distributional and molecular comparisons are necessary to better resolve these taxa.

\section{Acknowledgments}

Thanks to Pablo Melo, undergraduate students from the School of Biological and Environmental Sciences, USFQ and personnel from the Tiputini Biodiversity Station for help with collections. Drs David Hoel and John Reinert are acknowledged for valuable suggestions in final stages of the manuscript. This research was supported by NIH grants R01 AI-056254 and 1U19 AI-065866. In addition, LWC was supported by an NIH Parasitology Training grant PTG-2T32-AI07404 to Diane McMahon-Pratt.

\section{Literature Cited}

Alexander JB, Takaoka H, Eshita Y, Gomez EA, Hashiguchi Y. New records of phlebotomine sand flies (Diptera: Psychodidae) from Ecuador. Memorias do Instituto Oswaldo Cruz. 1992; 87:123130. [PubMed: 1343789]

Arzube MER. Los Phlebotomus de Ecuador. Relato de capturas no publicadas. Revista Ecuatoriana de Higiene y Medicina Tropical. 1960; 17:155-159. [PubMed: 13862705]

Bañuls AL, Jonquieres R, Guerrini F, Le Pont F, Barrera C, Espinel I, Guderian R, Echeverria R, Tibayrenc M. Genetic analysis of leishmania parasites in Ecuador: are Leishmania (Viannia) panamensis and Leishmania ( $V$.) guyanensis distinct taxa? American Journal of Tropical Medicine and Hygiene. 1999; 61:838-845. [PubMed: 10586922] 
Barretto M, Burbano ME, Barretto P. Lutzomyia sand flies (Diptera: Psychodidae) from middle and lower Putumayo Department, Colombia, with new records for the country. Memorias do Instituto Oswaldo Cruz. 2000; 95:633-639. [PubMed: 10998213]

Beati L, Cáceres AG, Lee JA, Munstermann LE. Systematic relationships among Lutzomyia sand flies (Diptera: Psychodidae) of Peru and Colombia based on the analysis of 12S and 28S ribosomal DNA sequences. International Journal of Parasitology. 2004; 34:225-234. [PubMed: 15037108]

Bejarano EE. Especies del género Lutzomyia (Diptera: Psychodidae) registradasen Colombia. Biomédica. 2007; 27(supplement 2):89-92.

Calvopina M, Armijos RX, Hashiguchi Y. Epidemiology of leishmaniasis in Ecuador: current status of knowledge-a review. Memorias do Instituto Oswaldo Cruz. 2004; 99:663-672. [PubMed: 15654419]

Cáceres AG, Galati EAB, Pinto J, Paredes R, Reategui R, Perez J, Chavarria L, Yanez H, Zorrila V. Psychodidae (Diptera) del Peru 1: Phlebotominae en Huanuco, Pasco y Cusco, su relacion con la enfermedad de Carrión y la leishmaniosis tegumentaria. Revista de Peru Biologia. 2000; 7:27-43.

Cáceres, AG.; Villaseca Castro, P. Serie Normas Técnicas. Instituto Nacional de Salud; Lima, Peru: 2002. Manual de procedimientos de identificacion de vectores de leishmaniosis y enfermedad de Carrión; p. 38

Dujardin JP, Le Pont F, Martinez E. Is Lutzomyia serrana (Diptera, Psychodidae, Phlebotominae) present in Ecuador? Parasite. 2004; 11:211-217. [PubMed: 15224583]

Dujardin JP, Le Pont F. Morphometrics of a neotropical sandfly species, Lutzomyia carrerai thula. Comptes Rendus de I'Academie des sciences Series III. 2000; 323:273-279.

Ferro, C.; Morales, A. Flebótomos de Colombia: studios realizados por el Laboratorio de Entomologia 1965-1997. In: Toro, G.; Hernández, CA.; Raad, J., editors. Instituto Nacional de Salud 19171997: una historia, un compromise. Instituto Nacional de Salud; Santa Fe de Bogotá: 1998. p. 219-233.414 pp.

Galati, EAB. Dissertation, Doctor of Philosophy. University of São Paulo; Brazil: 1990. Sistemática dos Phlebotominae (Diptera, Psychodidae) das Américas; p. 275

Galati, EAB. 2.1 Morpholologia e taxonomía. In: Rangel, EF.; Lainson, R., editors. Flebotomíneos do Brasil. Editora FIOC-RUZ; Rio de Janeiro: 2003. p. 23-52.p. 367

Gomez EAL, Hashiguchi Y. Monthly variation in natural infection of the sandfly Lutzomyia ayacuchensis with Leishmania mexicana in an endemic focus in the Ecuadorian Andes. Annals of Tropical Medicine and Parasitology. 1991; 85:407-411. [PubMed: 1796881]

Hashiguchi Y, Gomez EAL, de Coronel VV, Mimori T, Kawabata M, Furuya M, Nonaka S, Takaoka H, Alexander JB, Quizhpe AM, Grimaldi G, Kreutzer RD, Tesh RB. Andean leishmaniasis in Ecuador caused by infection with Leishmania mexicana and L. major-like parasites. American Journal of Tropical Medicine and Hygiene. 1991; 44:205-217. [PubMed: 1672799]

Le Pont F, León R, Mouchet J, Echevarria R, Guderian RH. Leishmaniose en Equateur. 2. Contacts homme/vecteurs de leishmaniose: cas de Lutzomyia trapidoi et Lu. gomezi. Annales de la Société belge de Médecine tropicale. 1994; 74:13-21.

Mouchet J, Le Pont F, León R, Echeverría R, Guderian RH. Leishmaniose en Equateur. 5. Leishmaniose et anthropisation sur la façade Pacific. Annales de la Société Belge de Médecine Tropicale. 1994; 74:35-41.

Rodríguez MJD. Los Phlebotomus del Ecuador (Díptera, Psychodidae). I. Consideraciones generales. Descripción de una nueva especie. Revista Ecuatoriana de Higiene y Medicina Tropical. 1950; 7:20-29.

Rodríguez MJD. Los Phlebotomus del Ecuador (Díptera, Psychodidae). III. Descripción de una nueva espécie. Revista Ecuatoriana de Higiene y Medicina Tropical. 1953; 10:51-55. [PubMed: 13237606]

Rodríguez MJD. Los Phlebotomus del Ecuador (Diptera, Psychodidae). VI. Nuevas capturas. Descripción de una nueva especie. Resumen y distribución geográfica. Revista Ecuatoriana de Higiene y Medicina Tropical. 1956; 13:75-82. [PubMed: 13389967]

Takaoka H, Gomez EAL, Alexander JB, Hashiguchi Y. Natural infection with Leishmania promastigotes in Lutzomyia ayacuchensis (Diptera: Psychodidae) in an Andean focus of Ecuador. Journal of Medical Entomology. 1990; 27:701-702. [PubMed: 2388245] 
Young DG. A review of the bloodsucking psychodid flies of Colombia (Diptera: Psychodidae). University of Florida Agricultural Experimental Station Technical Bulletin. 1979; 806:1-266.

Young, DG.; Duncan, MA. Memoirs of the American Entomological Institute. Associated Publishers; Gainesville, Florida: 1994. Guide to the identification and geographic distribution of Lutzomyia sand flies in Mexico, the West Indies, Central and South America (Diptera: Psychodidae); p. 881

Young DG, Rogers TE. The phlebotomine sand fly fauna (Diptera: Psychodidae) of Ecuador. Journal of Medical Entomology. 1984; 21:597-611. 


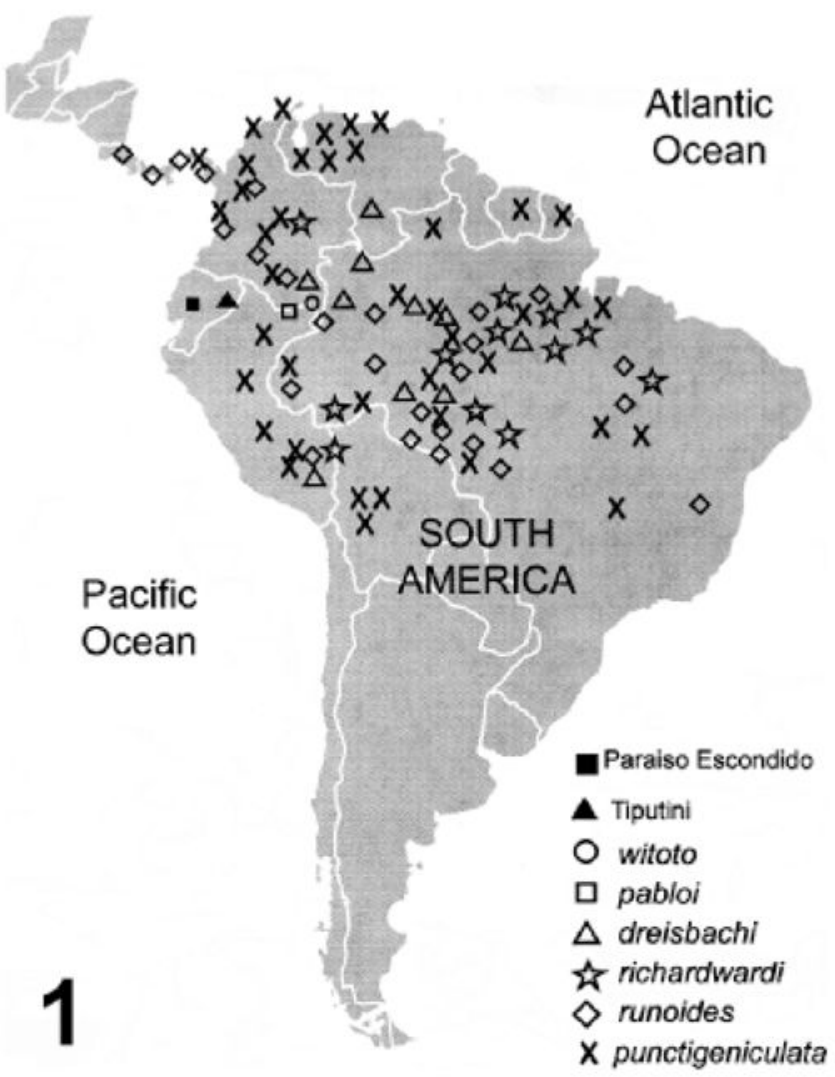

Fig. 1.

Species distributions of the six species newly identified in Ecuador. The geographic distributions were based on published species records. The six species were collected at Paraiso Escondido and Tiputini. 


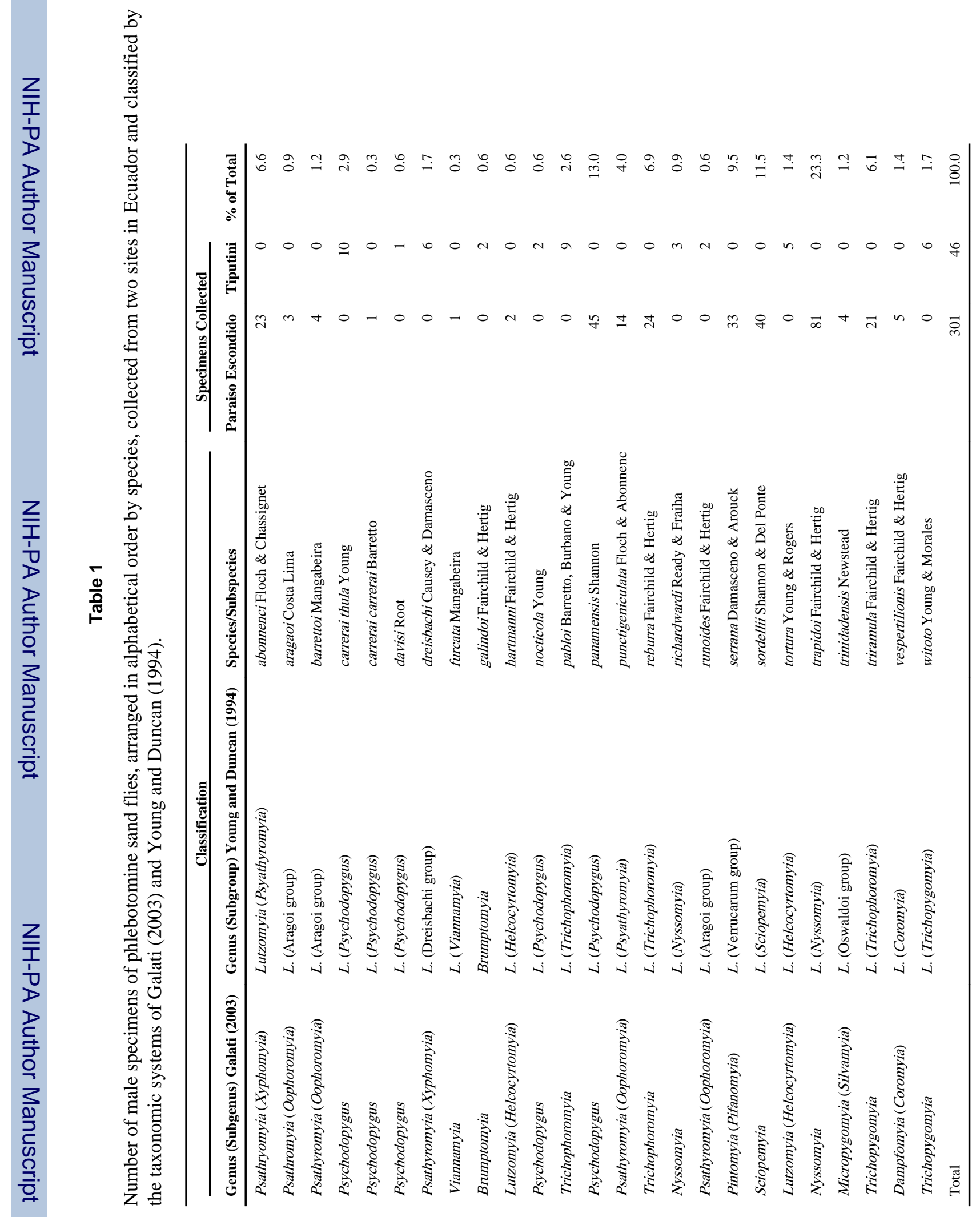

